\title{
Acute Exercise Increases Plasma Total Antioxidant Status and Antioxidant Enzyme Activities in Untrained Men
}

\author{
C. Berzosa, ${ }^{1}$ I. Cebrián, ${ }^{1}$ L. Fuentes-Broto, ${ }^{1}$ E. Gómez-Trullén, ${ }^{1}$ E. Piedrafita, ${ }^{1}$ \\ E. Martínez-Ballarín, ${ }^{1}$ L. López-Pingarrón, ${ }^{1}$ R. J. Reiter, ${ }^{2}$ and J. J. García ${ }^{1}$ \\ ${ }^{1}$ Department of Pharmacology and Physiology, Faculty of Medicine, University of Zaragoza, C/Domingo Miral s/n, \\ 50009 Zaragoza, Spain \\ ${ }^{2}$ Department of Cellular and Structural Biology, Health Science Center at San Antoni, University of Texas, TX 78229-3901, USA
}

Correspondence should be addressed to J. J. García, jjgarcia@unizar.es

Received 14 October 2010; Revised 19 December 2010; Accepted 3 January 2011

Academic Editor: M. Firoze Khan

Copyright ( $) 2011$ C. Berzosa et al. This is an open access article distributed under the Creative Commons Attribution License, which permits unrestricted use, distribution, and reproduction in any medium, provided the original work is properly cited.

\begin{abstract}
Antioxidant defences are essential for cellular redox regulation. Since free-radical production may be enhanced by physical activity, herein, we evaluated the effect of acute exercise on total antioxidant status (TAS) and the plasma activities of catalase, glutathione reductase, glutathione peroxidase, and superoxide dismutase and its possible relation to oxidative stress resulting from exercise. Healthy untrained male subjects $(n=34)$ performed three cycloergometric tests, including maximal and submaximal episodes. Venous blood samples were collected before and immediately after each different exercise. TAS and enzyme activities were assessed by spectrophotometry. An increase of the antioxidant enzyme activities in plasma was detected after both maximal and submaximal exercise periods. Moreover, under our experimental conditions, exercise also led to an augmentation of TAS levels. These findings are consistent with the idea that acute exercise may play a beneficial role because of its ability to increase antioxidant defense mechanisms through a redox sensitive pathway.
\end{abstract}

\section{Introduction}

In recent decades, intensive research in the field of oxidative damage indicates that exercise exacerbates the generation of reactive oxygen (ROS) and reactive nitrogen species (RNS), some of which are free-radicals [1-5]. A free-radical is any specie capable of existence with one or more unpaired electron [6]. ROS/RNS refer to oxygen or nitrogen containing free-radicals and their non-free-radical derivatives.

Aerobic organisms produce free-radicals as a consequence of the oxygen metabolism, and, obviously, exercise causes an increase in oxygen utilization in mitochondria, resulting in elevated radical generation. An estimated 2\% to $5 \%$ of the oxygen consumed $\left(\mathrm{VO}_{2}\right)$ during normal mitochondrial metabolism in aerobic organisms may be converted to radicals and their products [7]. During exercise, the $\mathrm{VO}_{2}$ uptake is higher than at rest [8] because of the increasing energy demand in many tissues, mainly in muscle.

The role of mitochondria in free-radical production during exercise is under investigation. The increase in oxygen uptake is related to substantial rise in the production of free-radicals generated during mitochondrial respiration [9]. Several potential alternative sources of free-radicals, such as oxidase systems associated with membranes, nitric oxide production, and phagocytic processes [3], as well as an increase in lactate formation, as happens in exhaustive exercise [10], have been proposed to contribute significantly to the overproduction of free-radicals.

The elevation of metabolism by exercise results in a greater production of superoxide radicals [11], which are dismutated to hydrogen peroxide $\left(\mathrm{H}_{2} \mathrm{O}_{2}\right)$ by superoxide dismutase (SOD). $\mathrm{H}_{2} \mathrm{O}_{2}$, a molecule that readily crosses cell membranes, can be detoxified to water and oxygen by other enzymes, that is, catalase (CAT) and glutathione peroxidase (GPx). But when these transformations do not take place, $\mathrm{H}_{2} \mathrm{O}_{2}$ is, via the Fenton reaction, converted to the hydroxyl radical, the most toxic ROS because of its high reactivity $[6,12]$.

Numerous studies have shown that muscle cells also release superoxide into the extracellular space $[11,13]$, so 
free-radicals readily reach the blood and act on other cells. There is a general consensus that free-radical generation during exercise occurs predominantly in skeletal and heart muscles; however, the invasive nature of obtaining biopsies from exercising humans limits their access. Therefore, some reports have claimed that the concentration of several oxidative stress markers increase immediately in the plasma after an acute exercise $[14,15]$.

All organisms have developed an antioxidant defence system to counter ROS/RNS production. Antioxidants are defined as any substance that, when present at low concentration compared to those of an oxidizable substrate, significantly delays or prevents the oxidation of that substrate [16]. They can be classified as enzymatic or nonenzymatic antioxidants. The first are low molecular weight proteins, which minimize oxidative damage by catalyzing chemical reactions to detoxify free-radicals in cells and tissues and can be synthesised due to the redox-activation of specific genes, primarily by affecting the binding of transcription factors to DNA. During exercise, free-radicals generated can activate different redox-sensitive transcription factors, including $\mathrm{NF}-\kappa \mathrm{B}$, which leads to an elevation in the expression of some antioxidant enzymes [17]. Nonenzymatic antioxidants are generally small molecules that directly scavenge ROS, preventing them from disfiguring lipids, proteins, or nucleic acids. Glutathione, an important intracellular antioxidant, is converted to its oxidized form (GSSG) by GPx when it is used as a scavenger; it is converted back to its reduced form by glutathione reductase (GR). Moreover, both animals and humans subjected to a long-term heavy exercise became more resistant to oxidative damage $[18,19]$. Fisher et al. studied the activity of SOD, CAT, and GPX after highintensity interval training, and they found that all of these enzymes activities were increased [20]. None of these studies have compared different types of exercise and observed changes in activities of four antioxidant enzymes and in the total antioxidant status in plasma.

Herein, we evaluated the antioxidant status after three protocols of acute exercise in untrained healthy men. Plasma samples were collected for the measurement of CAT, GR, GPx, and SOD activities and total antioxidant status (TAS) as a general marker of antioxidant defences.

\section{Material and Methods}

2.1. Subjects. Thirty-four healthy male volunteers, aged 19$29(23.0 \pm 0.41)$, were involved in this study. Only males were included to avoid any distortion in the hormonal response to physical exercise caused by sex differences [1]. Anthropometric characteristics of these subjects are summarized in Table 1.

None of the subjects participated regularly in sport competitions, and they did not engage in any form of vigorous exercise or take medications for 24 hours before the study was performed. All subjects underwent an extensive previous medical evaluation that included a history and physical examination, electrocardiogram, and biochemical profile to discard possible pathologies. Subjects gave their
TABle 1: Age, height, weight, body mass index (BMI), and ergometric parameters: maximal oxygen consumption $\left(\mathrm{VO}_{2 \max }\right)$ and maximal working capacity (MWC) during resting time. Results are means \pm SE of the 34 male healthy volunteers.

\begin{tabular}{lc}
\hline$n=34$ & Values \\
\hline Age $($ years $)$ & $23 \pm 0.41$ \\
Height $(\mathrm{cm})$ & $177.59 \pm 1.11$ \\
Weight $(\mathrm{kg})$ & $75.25 \pm 2.84$ \\
$\mathrm{BMI}\left(\mathrm{kg} / \mathrm{m}^{2}\right)$ & $23.72 \pm 0.69$ \\
$\mathrm{VO}_{2 \max }\left(\mathrm{mL} \cdot \mathrm{kg}^{-1} \cdot \mathrm{min}^{-1}\right)$ & $43.8 \pm 1.58$ \\
$\mathrm{MWC}(\mathrm{W})$ & $239.8 \pm 7.4$ \\
\hline
\end{tabular}

informed written consent to participate in the study, designed according to the principles of the Declaration of Helsinki (1964) and approved by the Ethical Committee of Clinical Investigation of Aragon with the statement code C02/2010.

2.2. Exercise Protocols. Exercise was performed on an electronically regulated cycloergometer between 08:00 and 10:30 a.m. after an overnight fast. All subjects pedaled at 60 rounds per minute. Three ergometric tests were performed on each subject in random order at intervals of at least 1 week. Firstly, the maximal oxygen consumption $\left(\mathrm{VO}_{2 \max }\right)$ and the maximal working capacity (MWC) were determined using a continuous progressive exercise test, where the work load was increased by 10 Watts every minute [21]. The oxygen uptake was determined using a "breath by breath" gas exchange analyzer (MedGrafics CPX Express). Secondly, all subjects performed a strenuous test until exhaustion at $\mathrm{VO}_{2 \max }$ intensity. The initial load was 100 Watts less than the MWC determined in the first test [22]. Finally, the subjects pedaled for 30 minutes at a submaximal workload chosen at $70 \%$ of the expected maximum for each individual [23].

2.3. Analytical Procedures. Peripheral venous blood samples obtained before exercise (A), and immediately after a continuous progressive exercise test (B), a strenuous test performed until exhaustion (C), and a submaximal exercise (70\% of the expected maximum workload) for 30 minutes (D) were drawn by antecubital venepuncture and collected into lithium heparin-containing tubes. $10 \mathrm{~mL}$ of blood were collected at each sampling time. Blood samples were immediately centrifuged at $1.000 \times \mathrm{g}$ for 10 minutes in a Beckman Allegra 64R refrigerated centrifuge (Fullerton, USA). Plasma was stored in $250 \mu \mathrm{L}$ aliquots at $-30^{\circ} \mathrm{C}$ until TAS and enzyme activities were determined.

The total antioxidant status method relies on the ability of plasma antioxidant substances to inhibit the oxidation of 2,2' -azino-di-[3-ethylbenzthiazioline sulphonate] (ABTS) to the radical cation $\mathrm{ABTS}^{+}$by metmyoglobin. This molecule formed a relative stable green substance which was measured spectrophotometrically at $600 \mathrm{~nm}$. Antioxidants in the sample decreased the formation of this colour proportional to their concentration [24]. The capacity of the antioxidants in the sample to prevent ABTS oxidation is compared with 
that of trolox, a water-soluble tocopherol analogue, and is quantified as millimolar trolox equivalents.

CAT activity was measured following the decrease in $\mathrm{H}_{2} \mathrm{O}_{2}$ concentration [25]. When $\mathrm{H}_{2} \mathrm{O}_{2}$ was added at low concentration $(0.2 \mathrm{M})$ to a sample with CAT, this enzyme catalyzed the transformation of this substrate to oxygen and water. To check the activity, a kinetic curve had to be measured during 30 seconds at $\lambda=240 \mathrm{~nm}$ using a molar extinction coefficient $43.6 \mathrm{~cm}^{-1} \mathrm{M}^{-1}$ [26] to know the amount of $\mathrm{H}_{2} \mathrm{O}_{2}$ eliminated.

Catalytic activity of GR was measured following the decrease in the absorbance at $\lambda=340 \mathrm{~nm}$ for 3 minutes due to the oxidation of NADPH to $\mathrm{NADP}^{+}$, in presence of GSSG, as described by Goldberg and Spooner [27]. The molar extinction coefficient is $\varepsilon=6.22 * 10^{3} \mathrm{~cm}^{-1} \mathrm{M}^{-1}$.

To determine GPx activity, the continuous decrease in NADPH concentration was measured, while GSH levels were maintained, following the Flohe and Gunzler method [28]. This method is based on the rise of the absorbance, during 3 minutes at $\lambda=340 \mathrm{~nm}$, because of the oxidation of NADPH in presence of GSH, t-butyl hydroperoxide, GR, and the sample. The molar extinction coefficient used for the calculations is $\varepsilon=6.22 * 10^{3} \mathrm{~cm}^{-1} \mathrm{M}^{-1}$.

One CAT, GR, or GPx enzymatic unit (units) was defined as that amount of the enzyme that catalyzes the conversion of 1 micromole of substrate per minute.

SOD activity was measured as the inhibition of the rate of reduction of cytochrome $\mathrm{c}$ by the superoxide radical $\left(\mathrm{O}_{2}{ }^{-}\right)$, observed at $550 \mathrm{~nm} . \mathrm{O}_{2}{ }^{-}{ }^{-}$was first produced by the reaction of xanthine and oxygen catalyzed by xanthine oxidase [29]. Cytochrome c molar extinction coefficient is $\varepsilon=27.6 *$ $10^{3} \mathrm{~cm}^{-1} \mathrm{M}^{-1}$ [30]. The definition of one unit of SOD is the amount of protein that inhibits the rate of cytochrome c reduction by $50 \%$.

2.3.1. Statistic Analysis. Data were analysed using repeatedmeasures ANOVAs. Where significant main effects were found, pairwise comparisons were conducted using Bonferroni adjustments for multiple comparisons. The level of statistical significance was $P<.05$.

\section{Results}

Total antioxidant status after all the three acute exercise protocols tested in this study: continuous progressive (1.62 $\pm 0.07)$, strenuous $(1.66 \pm 0.08)$ and submaximal exercises $(1.61 \pm 0.08)$ was elevated when compared with basal status $(1.53 \pm 0.07)$ as illustrated in Figure 1.

The strenuous protocol produced the highest increase in CAT activity $(42.29 \pm 2.84)$ although the continuous progressive $(24.85 \pm 2.35)$ and submaximal exercises $(29.19 \pm$ 3.89) also significantly elevated CAT activity relative to that at rest $(18.54 \pm 1.97)$ (Figure 2).

Both GR and GPx were elevated after submaximal exercises and even higher activity values of these enzymes were obtained after progressive and strenuous exercises (Figures 3 and 4). GR increases from a basal level of $0.021 \pm$ 0.002 to B: $0.031 \pm 0.003$, C: $0.031 \pm 0.003$, and D: $0.026 \pm$

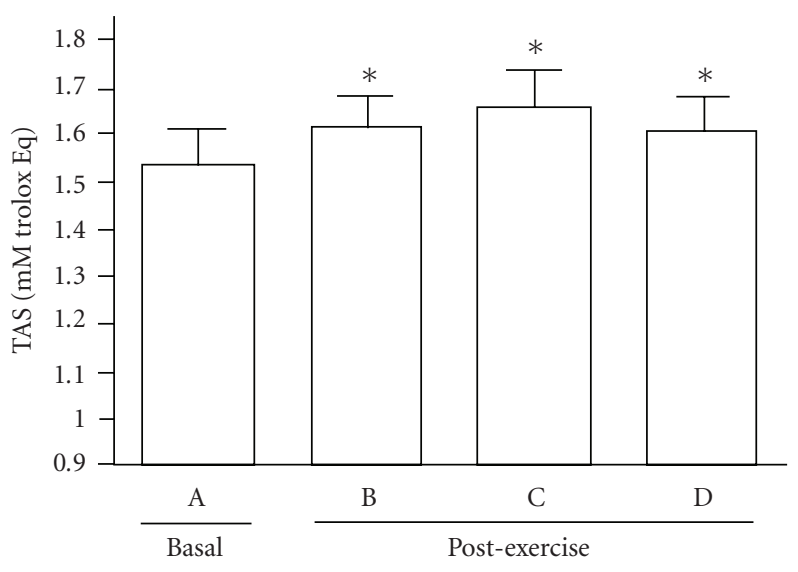

FIgURE 1: Total antioxidant status (TAS) in plasma from 34 male healthy subjects during basal (A) and immediately after a continuous progressive exercise test (B), a strenuous test performed until exhaustion $(\mathrm{C})$ and a submaximal exercise $(70 \%$ of the expected maximum workload) for 30 minutes (D). Data is expressed as mean \pm standard error. $*$ denotes statistical differences $(P<.05)$ versus basal status.

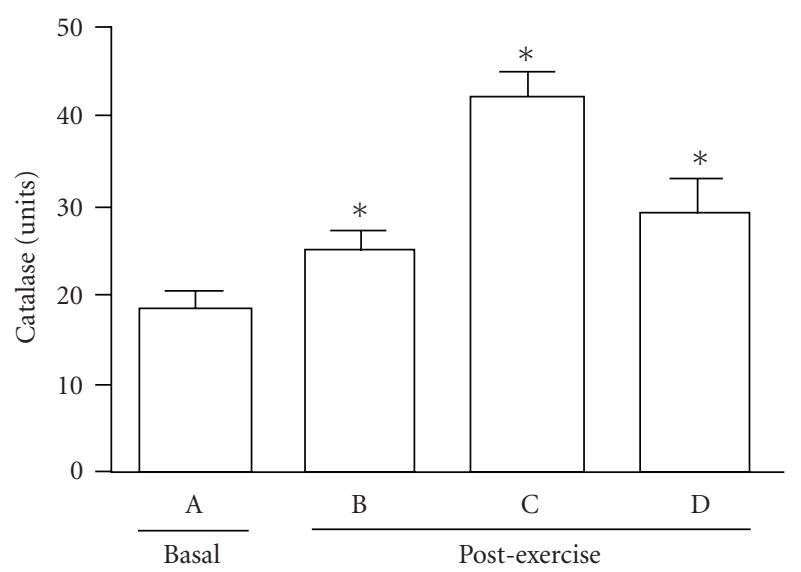

FIGURe 2: Catalase (CAT) activity in plasma from 34 male healthy subjects during basal (A) and immediately after exercise (B, C, and D). Data is expressed as mean \pm standard error. $*$ denotes statistical differences $(P<.05)$ versus $\mathrm{A}$.

0.003. GPx level was also higher after exercises B: $1.03 \pm 0.3$, C: $1.02 \pm 0.03$, and D: $1.02 \pm 0.03$ from a basal level of $0.94 \pm$ 0.02 .

The SOD activity rose significantly after the strenuous exercise $(0.028 \pm 0.007)$, but it is after the nonexhaustive test $(0.033 \pm 0.007)$ when the highest increase took place versus the basal value $(0.018 \pm 0.004)$ (Figure 5).

\section{Discussion}

Oxidative stress is an imbalance between ROS/RNS generation and antioxidants levels in favour of the former [31]. Although there is a general consensus that free-radical overproduction due to exercise occurs mainly in the active skeletal muscles [32-34], it is also well documented that 


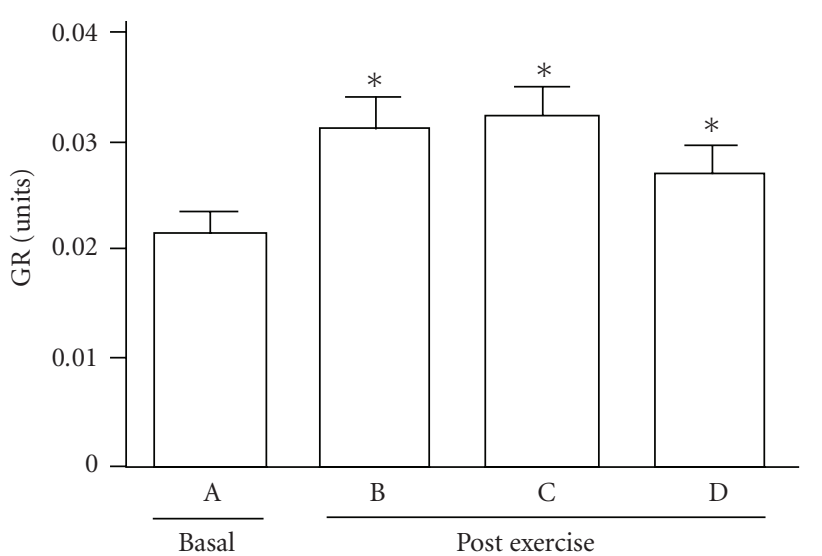

FIGURE 3: Glutathione reductase (GR) activity in plasma from 34 male healthy subjects during basal (A) and immediately after three exercise tests $(\mathrm{B}, \mathrm{C}$, and $\mathrm{D})$. Data is expressed as mean \pm standard error. $*$ denotes statistical differences $(P<.05)$ versus basal status.

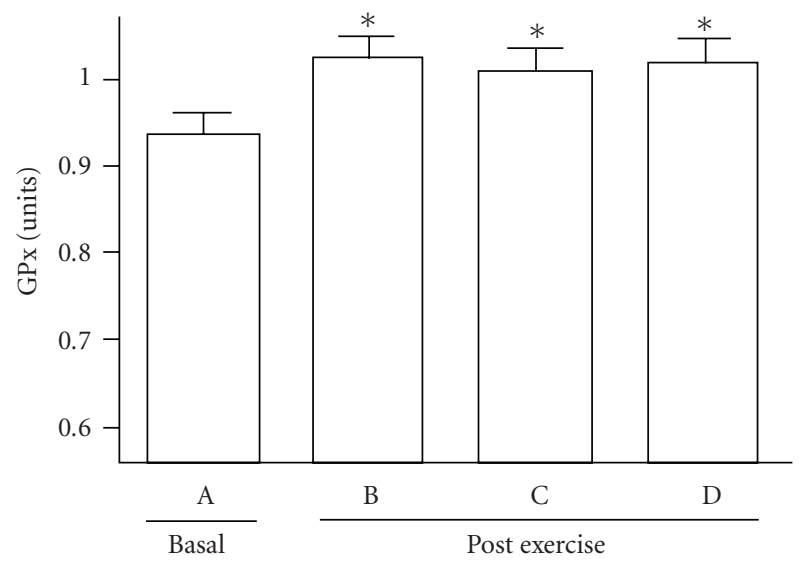

FIGURE 4: Plasma glutathione peroxidase (GPx) activity during basal (A) and immediately after a continuous progressive exercise test (B), a strenuous test performed until exhaustion (C) and a submaximal exercise (70\% of the expected maximum workload) for 30 minutes $(\mathrm{D}) . n=34$. Data is expressed as mean \pm standard error. $*$ denotes statistical differences $(P<.05)$ versus $\mathrm{A}$.

exercise causes systemic oxidative damage. Based on this, Sureda et al. [35] found an augmentation of malondialdehyde, a marker of lipid peroxidation due to oxidative stress, in lymphocytes after a single bout of intense exercise. In addition, Ajmani et al. [36] noted an increase in membrane rigidity in erythrocytes after a strenuous exercise because of oxidative stress. Membrane rigidity signifies elevated lipid peroxidation.

The main finding of our work was the increase of the TAS in human blood after a single bout of exercise, either maximal or submaximal. Plasma TAS is a combination of various antioxidant defences, including enzymatic and nonenzymatic systems. As shown herein, Child et al. [37] found higher TAS levels in the plasma after an exhaustive exercise, that is, equivalent to a half marathon, and they concluded that uric acid, an important component of the antioxidant system, is responsible for one third of the

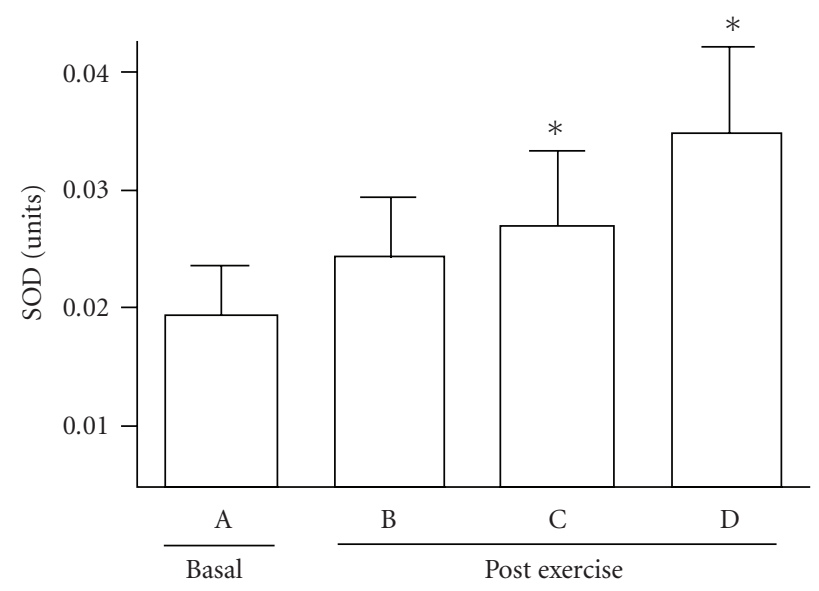

FIGURE 5: Superoxide dismutase (SOD) activity in plasma from 34 male healthy subjects during basal (A) and immediately after two exercise tests performed until exhaustion (B and $\mathrm{C}$ ) and a submaximal exercise (D). Data is expressed as mean \pm standard error. $*$ denotes statistical differences $(P<.05)$ versus basal status.

TAS increase. Although uric acid may contribute to the antioxidant defences, another possible explanation for the elevation of TAS is changes in other antioxidants, for example, GSH, melatonin, or the antioxidant enzymes [38]. We also demonstrate that CAT, GPx, GR, and SOD activities were higher after exercise than at rest.

Previous reports have shown increases of GPx, GR, and CAT activities in the skeletal muscle during exercise. Ji et al. $[39,40]$ observed in two consecutive studies that an acute bout of exercise increased antioxidant enzymatic activities in rat muscle. In the first report, rats performed an exercise in a treadmill until exhaustion [39]. The second study was designed to compare both maximal and submaximal protocols of exercise, and, as we found, GPx, GR, and CAT activities were enhanced by exercise [40]. SOD activity also increased after a single period of exhaustive exercise and during the recovery, following a nondamaging aerobic exercise in a cycloergometer [41]. In this report, muscle samples were taken from the vastus lateralis muscle of the exercised leg in humans by biopsy.

The effect of acute exercise on the antioxidant enzyme activities appears to be systemic, involving many organs. Following a single exhaustive swimming test, Terblanche [42] reported that CAT activity was higher compared to the rest in several tissues: liver, heart, kidney, or lung in male and in female rats; thereby, these authors proposed that increasing CAT activity during acute exercise may be a defence mechanism in protecting the tissues against hydrogen peroxide generation. Also, CAT and SOD activities in rat lung tissue was increased significantly after the effort in young rats, a response that was significantly depressed in old rats. This suggests that senescence entails a decrease in the antioxidant defence system [43]. Hara et al. [44] found an elevation of GPx activity in liver and muscle after a swimming test.

The invasive nature of obtaining muscular biopsies from exercising humans limits their access; thus, a number of 
studies have directed their efforts to the blood. Thus, Aguiló et al. [45] have recently found an elevation in CAT and GR activities in the erythrocytes, while Cases et al. [46] found CAT, GPx, and SOD rises in lymphocytes after a single bicycle ride or swimming. These authors proposed that oxidative stress and the necessity of protection against oxidative damage may be responsible, at least partially, for the elevation in the activity of these enzymes induced by exercise. However, CAT and GPx activities in human neutrophils decreased after a single bout of exercise [47], perhaps because these cells released the enzymes into the plasma. Consistent with our findings, Elosua et al. [48] also reported that the activity of extracellular SOD and GPx rose from basal status after an acute bout of aerobic. Although one hour later, during recovery, the antioxidant enzyme activities fell back to basal levels. However, enzyme activities were increased again 24 hours later because a possible genetic upregulation of these enzymes [48].

Recent interest has focused on the effect of training on the antioxidant defence system. Shin et al. [49] studied the effect of 6 months aerobic endurance training on the response to the acute exercise and reported that antioxidant enzyme activities were much higher than after pretraining test. A possible explanation for the reinforcement of the antioxidant system due to training is that exercise stimulates the expression of the genes involved in the regulation of the antioxidant enzymes in a redox sensitive signal transduction pathways, mainly NF- $\kappa \mathrm{B}$. It is reported the importance of the nuclear factor in the expression of SOD and inducible nitric oxide synthase (iNOS) in rat skeletal muscle [50]. Ji et al. [51] observed that exercising rats injected with allopurinol, a competitive inhibitor of xanthine oxidase, attenuated ROS production compared to untreated group, and also NF- $\kappa \mathrm{B}$ binding was dramatically enhanced by exercise but inhibited by allopurinol treatment. Thus, ROS produced by exercise seemed to be involved in NF- $\kappa \mathrm{B}$ signalling. It is also reported that physical exercise $\left(80 \% \mathrm{VO}_{2 \max }\right.$ for 1 hour) resulted in NF- $\kappa \mathrm{B}$ activation in peripheral blood cells of physically fit young men [52]. In the other hand, another study shows how an eccentric exercise for 45 minutes did not increase the expression of this transcription factor [53]. So, the influence of different exercise protocols of training in the redox status in many cells or tissues remains unclear $[48,54-57]$.

\section{Conclusions}

In conclusion, the data reported herein provide evidence that a single bout of maximal and submaximal acute exercise enhances plasma TAS in healthy human subjects. This increase may be a consequence of an improvement in the plasma activities of CAT, GPx, GR, and SOD. Based on our observations and previous studies which reported that exercise causes a significant augmentation of the concentrations of several antioxidant scavengers, presumably due to its interactions with the free-radical overproduction $[58,59]$, it seems reasonable to propose that exercise may play a beneficial role because of its ability to increase the antioxidant defense mechanisms against oxidative stress.

\section{Acknowledgments}

This work was supported by grants from the "Gobierno de Aragón" (Aging and Oxidative Stress Physiology, Grants nos. B40 and PI036/09) and by F.I.S. from Instituto de Salud Carlos III (Grant nos. RD06/0013/1017). The authors declare that they have no conflict of interests.

\section{References}

[1] R. J. Bloomer and K. H. Fisher-Wellman, "Blood oxidative stress biomarkers: influence of sex, exercise training status, and dietary intake," Gender Medicine, vol. 5, no. 3, pp. 218-228, 2008.

[2] M. J. Jackson, "Free radicals generated by contracting muscle: by-products of metabolism or key regulators of muscle function?” Free Radical Biology and Medicine, vol. 44, no. 2, pp. 132-141, 2008.

[3] S. K. Powers and M. J. Jackson, "Exercise-induced oxidative stress: cellular mechanisms and impact on muscle force production," Physiological Reviews, vol. 88, no. 4, pp. 12431276, 2008.

[4] K. J. A. Davies, A. T. Quintanilha, G. A. Brooks, and L. Packer, "Free radicals and tissue damage produced by exercise," Biochemical and Biophysical Research Communications, vol. 107, no. 4, pp. 1198-1205, 1982.

[5] M. C. Gomez-Cabrera, A. Martínez, G. Santangelo, F. V. Pallardó, J. Sastre, and J. Viña, "Oxidative stress in marathon runners: interest of antioxidant supplementation," The British Journal of Nutrition, vol. 96, supplement 1, pp. S31-S33, 2006.

[6] B. Halliwell, "Reactive oxygen species in living systems: source, biochemistry, and role in human disease," American Journal of Medicine, vol. 91, no. 3C, pp. 14S-22S, 1991.

[7] A. Boveris, N. Oshino, and B. Chance, "The cellular production of hydrogen peroxide," Biochemical Journal, vol. 128, no. 3, pp. 617-630, 1972.

[8] R. Cazzola, S. Russo-Volpe, G. Cervato, and B. Cestaro, "Biochemical assessments of oxidative stress, erythrocyte membrane fluidity and antioxidant status in professional soccer players and sedentary controls," European Journal of Clinical Investigation, vol. 33, no. 10, pp. 924-930, 2003.

[9] M. J. Jackson, D. Pye, and J. Palomero, "The production of reactive oxygen and nitrogen species by skeletal muscle," Journal of Applied Physiology, vol. 102, no. 4, pp. 1664-1670, 2007.

[10] M. A. Ali, F. Yasui, S. Matsugo, and T. Konishi, "The lactatedependent enhancement of hydroxyl radical generation by the Fenton reaction," Free Radical Research, vol. 32, no. 5, pp. 429438, 2000.

[11] F. McArdle, D. M. Pattwell, A. Vasilaki, A. McArdle, and M. J. Jackson, "Intracellular generation of reactive oxygen species by contracting skeletal muscle cells," Free Radical Biology and Medicine, vol. 39, no. 5, pp. 651-657, 2005.

[12] D. M. Patwell, A. McArdle, J. E. Morgan, T. A. Patridge, and M. J. Jackson, "Release of reactive oxygen and nitrogen species from contracting skeletal muscle cells," Free Radical Biology and Medicine, vol. 37, no. 7, pp. 1064-1072, 2004.

[13] M. B. Reid, T. Shoji, M. R. Moody, and M. L. Entman, "Reactive oxygen in skeletal muscle. II. Extracellular release of free radicals," Journal of Applied Physiology, vol. 73, no. 5, pp. 1805-1809, 1992.

[14] T. Ashton, C. C. Rowlands, E. Jones et al., "Electron spin resonance spectroscopic detection of oxygen-centred radicals 
in human serum following exhaustive exercise," European Journal of Applied Physiology and Occupational Physiology, vol. 77, no. 6, pp. 498-502, 1998.

[15] V. Pialoux, R. Mounier, E. Rock et al., "Effects of acute hypoxic exposure on prooxidant/antioxidant balance in elite endurance athletes," International Journal of Sports Medicine, vol. 30, no. 2, pp. 87-93, 2009.

[16] B. Halliwell, R. Aeschbach, J. Löliger, and O. I. Aruoma, "The characterization of antioxidants," Food and Chemical Toxicology, vol. 33, no. 7, pp. 601-617, 1995.

[17] M. C. Gomez-Cabrera, C. Borrás, F. V. Pallardo, J. Sastre, L. L. Ji, and J. Viña, "Decreasing xanthine oxidase-mediated oxidative stress prevents useful cellular adaptations to exercise in rats," Journal of Physiology, vol. 567, no. 1, pp. 113-120, 2005.

[18] M. Higuchi, L. J. Cartier, M. Chen, and J. O. Holloszy, "Superoxide dismutase and catalase in skeletal muscle: adaptive response to exercise," Journals of Gerontology, vol. 40, no. 3, pp. 281-286, 1985.

[19] S. K. Powers, D. Criswell, J. Lawler et al., "Influence of exercise and fiber type on antioxidant enzyme activity in rat skeletal muscle," American Journal of Physiology, vol. 266, no. 2, pp. R375-R380, 1994.

[20] G. Fisher, D. D. Schwartz, J. C. Quindry et al., "Lymphocyte enzymatic antioxidant responses to oxidative stress following high-intensity interval exercise," Journal of Applied Physiology. In press.

[21] P. Carta, G. Aru, M. T. Barbieri, and M. Mele, "Bicycle ergometry exercise tests: a comparison between 3 protocols with an increasing load," Medicina del Lavoro, vol. 82, no. 1, pp. 56-64, 1991.

[22] F. Caputo and B. S. Denadai, "Effects of aerobic endurance training status and specificity on oxygen uptake kinetics during maximal exercise," European Journal of Applied Physiology, vol. 93, no. 1-2, pp. 87-95, 2004.

[23] R. J. Bloomer, M. J. Falvo, A. C. Fry, B. K. Schilling, W. A. Smith, and C. A. Moore, "Oxidative stress response in trained men following repeated squats or sprints," Medicine and Science in Sports and Exercise, vol. 38, no. 8, pp. 14361442,2006

[24] N. J. Miller and G. Paganga, "Antioxidant activity of lowdensity lipoprotein," Methods in Molecular Biology, vol. 108, pp. 325-335, 1998.

[25] D. M. Aebi, H.E., "Catalase," in Methods of Enzymatic Analysis, H. U. Bergmeyer, J. Bergmeyer, and M. Grassl, Eds., pp. 273286, Verlag Chemie, Weinheim, Germany, 1983.

[26] C. R. Wheeler, J. A. Salzman, N. M. Elsayed, S. T. Omaye, and D. W. Korte, "Automated assays for superoxide dismutase, catalase, glutathione peroxidase, and glutathione reductase activity," Analytical Biochemistry, vol. 184, no. 2, pp. 193-199, 1990.

[27] D. M. Goldberg and R. J. Spooner, “Glutathione reductase," in Methods of Enzymatic Analysis, H. U. Bergmeyer, J. Bergmeyer, and M. Grassl, Eds., pp. 258-266, Verlag Chemie, Weinheim, Germany, 1983.

[28] L. Flohe and W. A. Gunzler, "Assays of glutathione peroxidase," Methods in Enzymology, vol. 105, pp. 114-121, 1984.

[29] C. C. Winterbourn, R. E. Hawkins, M. Brian, and R. W. Carrell, "The estimation of red cell superoxide dismutase activity," Journal of Laboratory and Clinical Medicine, vol. 85, no. 2, pp. 337-341, 1975.

[30] T. A. Alleyne, M. T. Wilson, G. Antonini et al., "Investigation of the electron-transfer properties of cytochrome $\mathrm{c}$ oxidase covalently cross-linked to Fe- or Zn-containing cytochrome c," Biochemical Journal, vol. 287, no. 3, pp. 951-956, 1992.

[31] H. Sies and R. Mehlhorn, "Mutagenicity of nitroxide-free radicals," Archives of Biochemistry and Biophysics, vol. 251, no. 1, pp. 393-396, 1986.

[32] M. J. Jackson, "Reactive oxygen species and redox-regulation of skeletal muscle adaptations to exercise," Philosophical Transactions of the Royal Society B, vol. 360, no. 1464, pp. 2285-2291, 2005.

[33] A. McArdle, D. Pattwell, A. Vasilaki, R. D. Griffiths, and M. J. Jackson, "Contractile activity-induced oxidative stress: cellular origin and adaptive responses," American Journal of Physiology, vol. 280, no. 3, pp. C621-C627, 2001.

[34] J. Viña, M. C. Gomez-Cabrera, A. Lloret et al., "Free radicals in exhaustive physical exercise: mechanism of production, and protection by antioxidants," IUBMB Life, vol. 50, no. 4-5, pp. 271-277, 2000.

[35] A. Sureda, M. D. Ferrer, P. Tauler et al., "Effects of exercise intensity on lymphocyte $\mathrm{H} 2 \mathrm{O} 2$ production and antioxidant defences in soccer players," British Journal of Sports Medicine, vol. 43, no. 3, pp. 186-190, 2009.

[36] R. S. Ajmani, J. L. Fleg, A. A. Demehin et al., "Oxidative stress and hemorheological changes induced by acute treadmill exercise," Clinical Hemorheology and Microcirculation, vol. 28, no. 1, pp. 29-40, 2003.

[37] R. B. Child, D. M. Wilkinson, J. O. L. Fallowfield, and A. E. Donnelly, "Elevated serum antioxidant capacity and plasma malondialdehyde concentration in response to a simulated half-marathon run," Medicine and Science in Sports and Exercise, vol. 30, no. 11, pp. 1603-1607, 1998.

[38] B. P. Yu, "Cellular defenses against damage from reactive oxygen species," Physiological Reviews, vol. 74, no. 1, pp. 139$162,1994$.

[39] L. L. Ji and R. Fu, "Responses of glutathione system and antioxidant enzymes to exhaustive exercise and hydroperoxide," Journal of Applied Physiology, vol. 72, no. 2, pp. 549-554, 1992.

[40] L. L. Ji, R. Fu, and E. W. Mitchell, "Glutathione and antioxidant enzymes in skeletal muscle: effects of fiber type and exercise intensity," Journal of Applied Physiology, vol. 73, no. 5, pp. 1854-1859, 1992.

[41] M. Khassaf, R. B. Child, A. McArdle, D. A. Brodie, C. Esanu, and M. J. Jackson, "Time course of responses of human skeletal muscle to oxidative stress induced by nondamaging exercise," Journal of Applied Physiology, vol. 90, no. 3, pp. 10311035, 2001.

[42] S. E. Terblanche, "The effects of exhaustive exercise on the activity levels of catalase in various tissues of male and female rats," Cell Biology International, vol. 23, no. 11, pp. 749-753, 1999.

[43] H. Hatao, S. Oh-Ishi, M. Itoh et al., "Effects of acute exercise on lung antioxidant enzymes in young and old rats," Mechanisms of Ageing and Development, vol. 127, no. 4, pp. 384-390, 2006.

[44] M. Hara, M. Abe, T. Suzuki, and R. J. Reiter, "Tissue changes in glutathione metabolism and lipid peroxidation induced by swimming are partially prevented by melatonin," Pharmacology and Toxicology, vol. 78, no. 5, pp. 308-312, 1996.

[45] A. Aguiló, P. Tauler, E. Fuentespina, J. A. Tur, A. Córdova, and A. Pons, "Antioxidant response to oxidative stress induced by exhaustive exercise," Physiology and Behavior, vol. 84, no. 1, pp. 1-7, 2005.

[46] N. Cases, A. Sureda, I. Maestre et al., "Response of antioxidant defences to oxidative stress induced by prolonged exercise: 
antioxidant enzyme gene expression in lymphocytes," European Journal of Applied Physiology, vol. 98, no. 3, pp. 263-269, 2006.

[47] M. D. Ferrer, P. Tauler, A. Sureda, J. A. Tur, and A. Pons, "Antioxidant regulatory mechanisms in neutrophils and lymphocytes after intense exercise," Journal of Sports Sciences, vol. 27, no. 1, pp. 49-58, 2009.

[48] R. Elosua, L. Molina, M. Fito et al., "Response of oxidative stress biomarkers to a 16-week aerobic physical activity program, and to acute physical activity, in healthy young men and women," Atherosclerosis, vol. 167, no. 2, pp. 327-334, 2003.

[49] Y. A. Shin, J. H. Lee, W. Song, and T. W. Jun, "Exercise training improves the antioxidant enzyme activity with no changes of telomere length," Mechanisms of Ageing and Development, vol. 129, no. 5, pp. 254-260, 2008.

[50] M. C. Gomez-Cabrera, E. Domenech, and J. Viña, "Moderate exercise is an antioxidant: upregulation of antioxidant genes by training," Free Radical Biology and Medicine, vol. 44, no. 2, pp. 126-131, 2008.

[51] L. L. Ji, M. C. Gomez-Cabrera, and J. Vina, "Role of nuclear factor $\kappa \mathrm{B}$ and mitogen-activated protein kinase signaling in exercise-induced antioxidant enzyme adaptation," Applied Physiology, Nutrition and Metabolism, vol. 32, no. 5, pp. 930935, 2007.

[52] J. Vider, D. E. Laaksonen, A. Kilk et al., "Physical exercise induces activation of NF- $\kappa \mathrm{B}$ in human peripheral blood lymphocytes," Antioxidants and Redox Signaling, vol. 3, no. 6, pp. 1131-1137, 2001.

[53] T. W. Buford, M. B. Cooke, B. D. Shelmadine, G. M. Hudson, L. Redd, and D. S. Willoughby, "Effects of eccentric treadmill exercise on inflammatory gene expression in human skeletal muscle," Applied Physiology, Nutrition and Metabolism, vol. 34, no. 4, pp. 745-753, 2009.

[54] L. A. da Silva, C. A. Pinho, L. G. C. Rocha, T. Tuon, P. C. L. Silveira, and R. A. Pinho, "Effect of different models of physical exercise on oxidative stress markers in mouse liver," Applied Physiology, Nutrition and Metabolism, vol. 34, no. 1, pp. 6065, 2009.

[55] R. H. Lambertucci, A. C. Levada-Pires, L. V. Rossoni, R. Curi, and T. C. Pithon-Curi, "Effects of aerobic exercise training on antioxidant enzyme activities and mRNA levels in soleus muscle from young and aged rats," Mechanisms of Ageing and Development, vol. 128, no. 3, pp. 267-275, 2007.

[56] R. A. Pinho, M. E. Andrades, M. R. Oliveira et al., "Imbalance in SOD/CAT activities in rat skeletal muscles submitted to treadmill training exercise," Cell Biology International, vol. 30, no. 10 , pp. 848-853, 2006.

[57] S. K. Powers and D. Criswell, "Adaptive strategies of respiratory muscles in response to endurance exercise," Medicine and Science in Sports and Exercise, vol. 28, no. 9, pp. 1115-1122, 1996.

[58] J. C. B. Ferreira, A. V. Bacurau, C. R. Bueno Jr. et al., "Aerobic exercise training improves Ca handling and redox status of skeletal muscle in mice," Experimental Biology and Medicine, vol. 235, no. 4, pp. 497-505, 2010.

[59] E. Serrano, C. Venegas, G. Escames et al., "Antioxidant defence and inflammatory response in professional road cyclists during a 4-day competition," Journal of Sports Sciences, vol. 28, no. 10, pp. 1047-1056, 2010. 

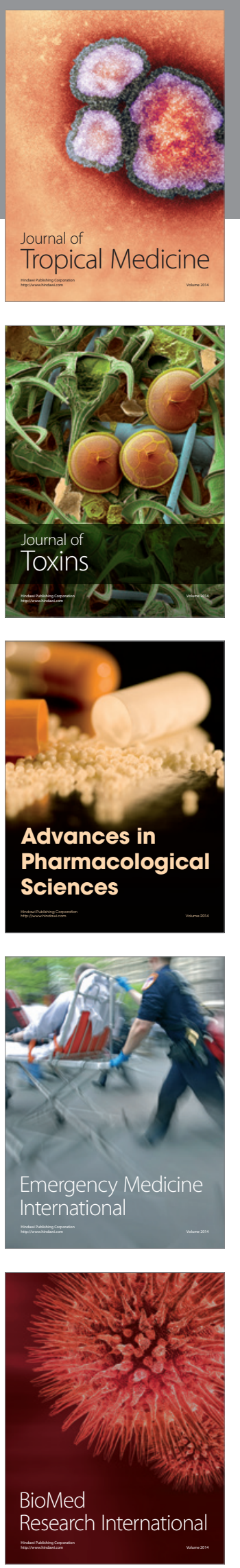
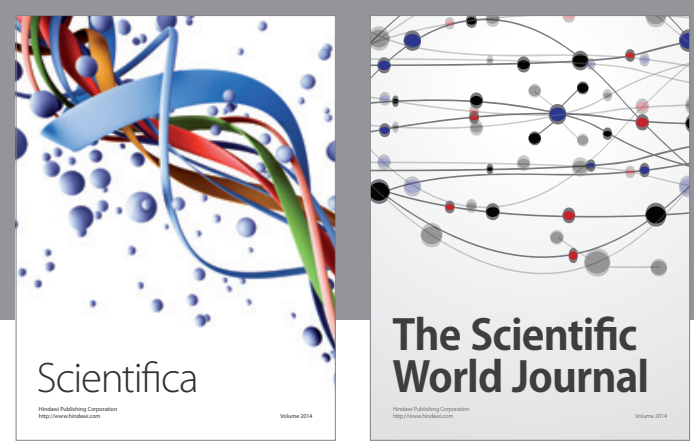

The Scientific World Journal
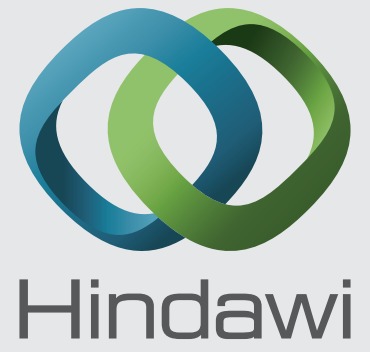

Submit your manuscripts at

http://www.hindawi.com
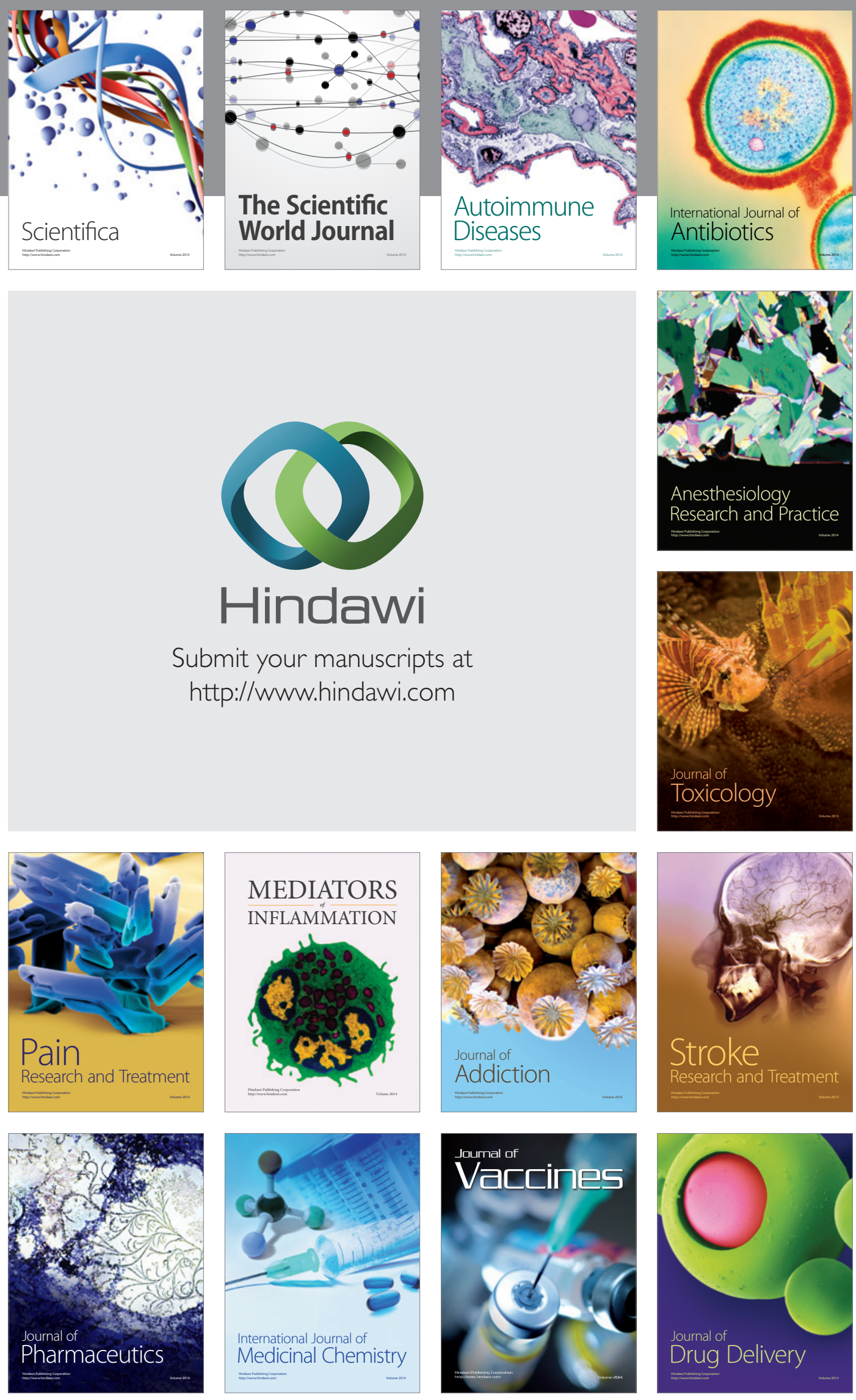